\title{
RANCANG BANGUN SISTEM KONTROLTEMPERATUR BERBASIS LOGIKA FUZZY
}

\author{
DESIGN AND CONSTRUCTION FUZZY LOGIC \\ TEMPERATURECONTROL SYSTEM
}

\author{
Ardiyanto Happy Susilo, Ninik Purwati, I.G. Puja Astawa, Arna Fariza
}

\author{
Jurusan Teknik Telekomunikasi, Politeknik Elektronika Negeri Surabaya \\ Kampus ITS Keputih Sukolilo, Surabaya 60111 \\ Telp. 62-31-5947280, 5946114, Fax. 62-31-5946114 \\ e-mail : 4ever_nn@eudoramail.com
}

\begin{abstract}
Abstrak
Kontroler fuzzy merupakan salah satu metode sistem kontrol yang menyatakan hokum operasional dari suatu sistem dengan ungkapan bahasa, bukan dengan persamaan matematis. Pada proyek akhir ini, kontroler fuzzy digunanakan sebagai kontrol temperatur yang diharapkan mampu mengontrol temperatur sesuai dengan setting point yang diinginkan. Prinsip kerjanya yaitu sinyal masukan dari plant yang berupa sinyal error dan diferensial error diolah oleh sistem logika fuzzy melalui tiga proses ; fuzzyfikasi, rule base dan defuzzyfikasi, menjadi sinyal kontrol yang mampu menentukan sudut pengapian dari SCR dalam menyalakan heater sebagai pemanas . Proses looping berlangsung terus menerus sampai didapatkan nilai temperatur yang sesuai atau mendekati dengan setting point yang dimasukkan.
\end{abstract}

\begin{abstract}
Fuzzy controller is one of control system method which approximately the operational law from a system with language expression, not with mathenatic equation. In this final project, fuzzy controller is used as temperature control which wish able to control temperature the same as the setting point that wanted. The work principle is input signals from the plant; error signal and error diferential signal, are processed by fuzzy logic system through three process are fuzzyfication, rule base, and defuzzyfication, become control signal which able to determine the angle of SCR as driver which is used to flame heater as heating. The looping process continues until it's get temperature value closer as setting point which is inputed.
\end{abstract}




\section{Pendahuluan}

Sistem kontrol logika fuzzy memiliki beberapa keunggulan dibandingkan dengan sistem kontrol konvensional, diantaranya : mampu mengontrol sistem-sistem kompleks tanpa harus mengetahui model mathematis sistem, dapat beroperasi secara real time, sederhana dan mudah diterapkan. Berdasarkan keunggulan tersebut maka pada proyek akhir ini, kami mencoba menerapkan sistem kontrol logika fuzzy untuk mengontrol temperatur. Dengan fuzzy logic control, diharapkan mampu mengontrol temperatur sesuai dengan setting point yang inginkan.

\section{Perencanaan dan Pembuatan Sistem \\ II. 1. Blok Diagram Sistem}

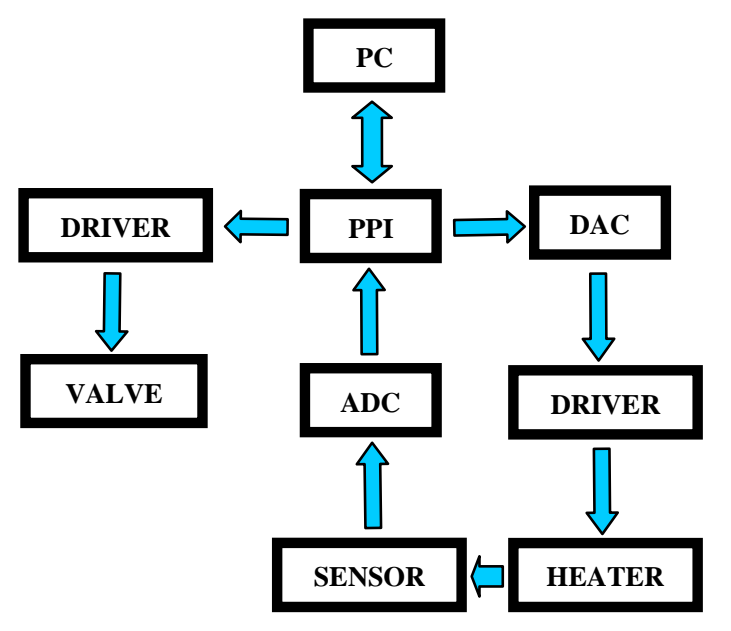

Gambar 2.1. Blok Diagram System

\section{II.1.1. Personal Computer}

Pada personal computer terdapat program kontrol logika fuzzy yang menggunakan bahasa pemrograman $\mathrm{C}++$. Kontrol logika fuzzy mengolah masukan dari sensor temperatur yang berupa sinyal error dan diferensial error menjadi sinyal kontrol. Prosesnya melalui tiga tahap yaitu fuzzyfikasi, rule base, dan defuzzyfikasi.

\section{II.1.2. PPI 8255}

PPI 8255 merupakan penjembatan antara hardware dan PC (software). PPI 8255 mempunyai 24 pin I/O yang terdiri dari 3 port, yaitu Port A (8pin), Port B (8 pin) dan Port C ( 8 pin).pada port A dan C kita gunakan sebagai output sedangkan pada port $\mathrm{B}$ sebagai input.

\section{II.1.3. Driver}

Pada rangkaian driver, digunakan SCR sebagai penentu besarnya sudut pengapian yang merupakan awal kerja heater. Sedangkan untuk valve, SCR digunakan sebagai 
switch on-of saja. Sudut pengapian dari SCR sendiri ditentukan oleh sinyal kontrol yang diberikan oleh kontrol logika fuzzy.

\section{II.1.4. Heater dan Valve}

Heater digunakan untuk memanaskan air dalam bejana sedangkan sebagai pendingin digunakan air pula yang dikontrol oleh valve.

\section{II.1.5. Sensor}

Sensor yang digunakan yaitu IC LM 335 yang memiliki kharakteristik setiap kenaikan suhu sebesar $1^{\circ} \mathrm{K}$ maka terjadi kenaikan tegangan sebesar $10 \mathrm{mV}$. Sensor ini berfungsi mendeteksi perubahan temperatur dari plant dan mangumpanbalikkannya ke kontrol logika fuzzy.

\section{II.1.6. ADC ( Analog to Digital Conversion )}

ADC berfungsi mengubah sinyal analog yang diberikan oleh sensor menjadi sinyal digital yang kemudian dikirim ke kontrol logika fuzzy melalui PPI 8255.

\section{II.1.7. DAC ( Digital to Analog Conversion )}

DAC berfungsi mengubah sinyal digital yang diberikan oleh kontrol logika fuzzy melalui PPI 8255, menjadi sinyal analog yang mementukan besarnya sudut pengapian dari SCR.

\section{II.1.8. Flowchart}

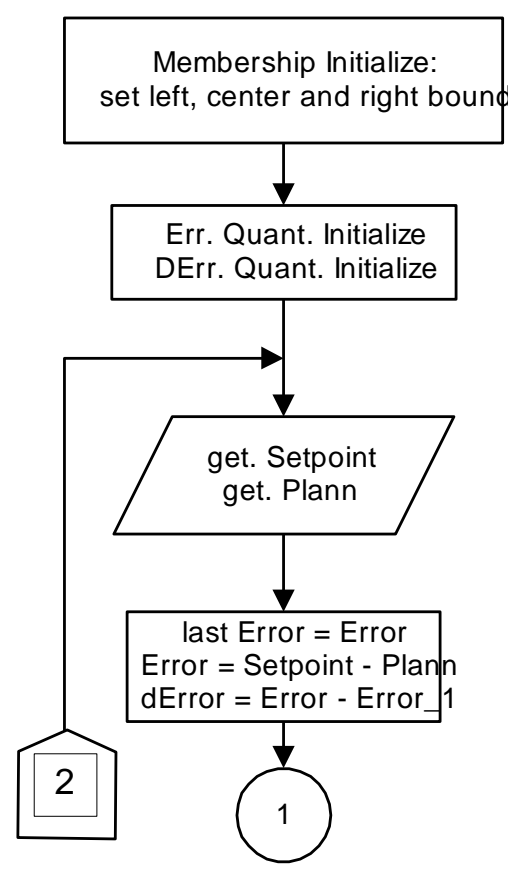




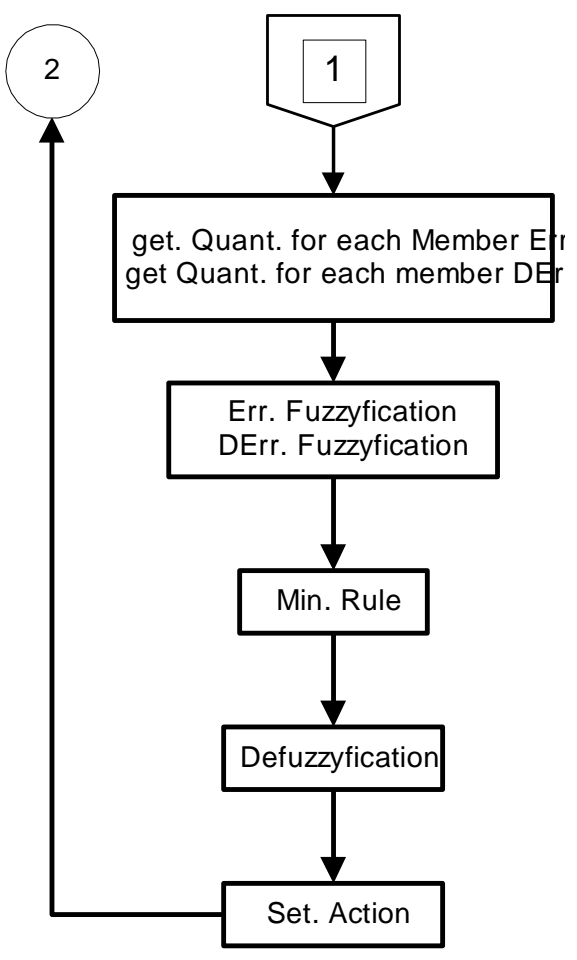

\section{II.2. Cara Kerja}

Setting point dimasukkan. Sensor mendeteksi perubahan temperatur pada plant dan mengumpanbalikkannya ke kontrol logika fuzzy melalui PPI 8255. Tapi sebelum melalui PPI, sinyal dari sensor yang telah dikuatkan diubah terlabih dahulu oleh ADC menjadi sinyal digital karena masih berupa sinyal analog. Oleh kontrol logika fuzzy, sinyal masukan dari sensor digunakan untuk mencari besarnya error dan diferensial error dengan rumus sebagai berikut :

error $=$ setting point - output

$\mathrm{dError}=$ error - error $\_1$

Sinyal error dan diferensial error diolah menjadi sinyal kontrol melalui tiga tahap yaitu fuzzyfikasi, rule base dan defuzzyfikasi. Sinyal kontrol dari sistem logika fuzzy menentukan penyalaan heater dan valve yang dikontrol melalui driver yang berupa SCR. Untuk menyalakan heater, terlebih dahulu sinyal kontrol dari kontrol logika fuzzy yang masih berupa sinyal digital diubah terlebih dahulu oleh DAC menjadi sinyal analog. Sinyal analog inilah yang nantinya menentukan besarnya sudut pengapian dari SCR yang dipakai untuk menyalakan heater. Sedangkan untuk penyalaan valve, tidak diperlukan DAC karena untuk menyalakan valve hanya diperlukan sinyal biner ' 1 ' atau ' 0 '. Jika temperatur $<$ setting point maka heater nyala dan valve mati. Jika temperatur > setting point maka heater mati dan valve hidup. Sensor akan kembali mendeteksi perubahan dari plant dan mengumpanbalikkannya ke kontrol logika fuzzy. Proses looping berlangsung terus sampai didapatkan temperatur sesuai dengan setting point yang dimasukkan. 


\section{Analisa dan Hasil Pengukuran}

\section{III.1. Pengujian Rangkaian DAC}

Pengujian ini dimaksudkan untuk mengecek keluaran dari DAC yang merupakan konversi digital dari sinyal kontrol fuzzy ke analog. Adapun hasil pengukurannya dapat dilihat pada tabel di bawah ini :

Tabel 3.1.Hasil Pengukuran output DAC

\begin{tabular}{|c|c|c|c|}
\hline Bit DAC & $\begin{array}{l}\text { Tegangan } \\
\text { Output } \\
\text { (DAC) Volt }\end{array}$ & Bit DAC & $\begin{array}{c}\text { Tegangan } \\
\text { Output } \\
\text { (DAC) Volt }\end{array}$ \\
\hline 0 & 0 & 125 & 5,73 \\
\hline 5 & 0,22 & 130 & 5,96 \\
\hline 10 & 0,46 & 135 & 6,19 \\
\hline 15 & 0,68 & 140 & 6,42 \\
\hline 20 & 0,91 & 145 & 6,65 \\
\hline 25 & 1,14 & 150 & 6,88 \\
\hline 30 & 1,37 & 155 & 7,11 \\
\hline 35 & 1,6 & 160 & 7,84 \\
\hline 40 & 1,83 & 165 & 7,56 \\
\hline 45 & 2 & 170 & 7,8 \\
\hline 50 & 2,29 & 175 & 8,02 \\
\hline 55 & 2,52 & 180 & 8,25 \\
\hline 60 & 2,75 & 185 & 8,48 \\
\hline 65 & 2,98 & 190 & 8,71 \\
\hline 70 & 3,21 & 195 & 8,94 \\
\hline 75 & 3,44 & 200 & 9,17 \\
\hline 80 & 3,67 & 205 & 9,4 \\
\hline 85 & 3,89 & 210 & 9,63 \\
\hline 90 & 4,13 & 215 & 9,85 \\
\hline 95 & 4,35 & 220 & 10,09 \\
\hline 100 & 4,58 & 225 & 10,81 \\
\hline 105 & 4,81 & 230 & 10,54 \\
\hline 110 & 5,04 & 235 & 10,77 \\
\hline 115 & 5,27 & 240 & 10,9 \\
\hline 120 & 5,5 & & \\
\hline
\end{tabular}

Dari tabel di atas maka dapat diketahui bahwa kenaikan setiap satu bit akan menyebabkan tegangan sebesar 0,04 Volt sampai dengan 0,05 Volt. Selain itu data kenaikan DAC hanya sampai pada 240 bit dengan tegangan sebesar 10,9 Volt. Hal ini mungkin dikarenakan kemampuan dari IC DAC yang kurang bagus dan tegangan referensi yang tidak sampai 12 Volt.

\section{III.2. Pengujian Pengukuran Suhu dan Output IC LM 335}

Tujuan dari pengukuran ini untuk mengetahui kharakteristik IC LM 335 dan kelinieritasannya sebagai sensor suhu pada air.

Adapun hasil pengukurannya dapat dilihat pada tabel di bawah ini : 
Tabel 3.2. Pengukuran Temperatur dengan IC LM 335

\begin{tabular}{|c|c|c|c|c|c|}
\hline No & $\begin{array}{c}\text { Suhu } \\
\text { (Celcius } \\
\text { ) }\end{array}$ & $\begin{array}{c}\text { Tegangan } \\
\text { (Volt) }\end{array}$ & No & $\begin{array}{c}\text { Suhu } \\
\text { (Celcius ) }\end{array}$ & $\begin{array}{c}\text { Tegangan } \\
\text { ( Volt ) }\end{array}$ \\
\hline 1 & 27 & 3,00 & 27 & 53 & $\mathbf{3 , 3 5}$ \\
\hline 2 & 28 & 3,02 & 28 & 54 & 3,36 \\
\hline 3 & 29 & 3,04 & 29 & 55 & 3,37 \\
\hline 4 & 30 & 3,06 & 30 & 56 & 3,38 \\
\hline 5 & 31 & 3,08 & 31 & 57 & $\mathbf{3 , 4 0}$ \\
\hline 6 & 32 & 3,10 & 32 & 58 & 3,41 \\
\hline 7 & 33 & 3,12 & 33 & 59 & 3,42 \\
\hline 8 & 34 & 3,14 & 34 & 60 & 3,43 \\
\hline 9 & 35 & 3,15 & 35 & 61 & 3,44 \\
\hline 10 & 36 & $\mathbf{3 , 1 7}$ & 36 & 62 & 3,45 \\
\hline 11 & 37 & 3,18 & 37 & 63 & 3,46 \\
\hline 12 & 38 & 3,20 & 38 & 64 & $\mathbf{3 , 4 7}$ \\
\hline 13 & 39 & 3,21 & 39 & 65 & 3,48 \\
\hline 14 & 40 & 3,22 & 40 & 66 & 3,48 \\
\hline 15 & 41 & 3,23 & 41 & 67 & 3,49 \\
\hline 16 & 42 & 3,24 & 42 & 68 & $3, \mathbf{3 0}$ \\
\hline 17 & 43 & 3,25 & 43 & 69 & $\mathbf{3 , 5 0}$ \\
\hline 18 & 44 & 3,26 & 44 & 70 & 3,51 \\
\hline 19 & 45 & 3,27 & 45 & 71 & 3,51 \\
\hline 20 & 46 & 3,29 & 46 & 72 & 3,52 \\
\hline 21 & 47 & $\mathbf{3 , 3 0}$ & 47 & 73 & $\mathbf{3 , 5 3}$ \\
\hline 22 & 48 & 3,31 & 48 & 74 & 3,53 \\
\hline 23 & 49 & 3,32 & 49 & 75 & 3,54 \\
\hline 24 & 50 & 3,33 & \begin{tabular}{|l|}
50 \\
\end{tabular} & 76 & 3,54 \\
\hline 25 & 51 & 3,34 & 51 & 77 & 3,55 \\
\hline 26 & 52 & 3,34 & & & \\
\hline
\end{tabular}

Dari hasil pengukuran suhu dan output IC LM 335 didapatkan gambar grafik seperti di bawah ini :

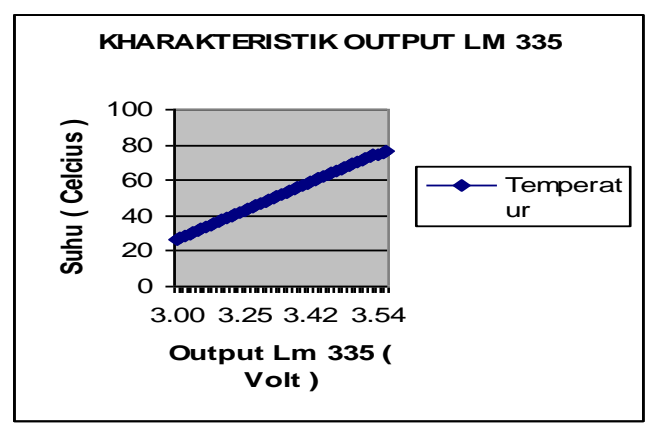

Gambar 3.1.

Kharakteristik Output

335 
Dari gambar di atas terlihat bahwa kharakteristik output dari IC LM 335 adalah linier. Hal ini karena skala grafik terlalu kecil sehingga penyimpangannya tidak kelihatan.

Dari tabel hasil pengukuran diketahui bahwa kenaikan tegangan tiap derajatnya tidak seperti dalam teori yang menyatakan tiap kenaikan suhu 1 derajat diikuti oleh kenaikan tagangan $10 \mathrm{mV}$. Dimana pada hasil pengukuran tampak bahwa ada kenaikan tegangan $20 \mathrm{mV}$ sampai dengan $30 \mathrm{mV}$ untuk kenaikan suhu 1 derajat. Hal ini dikarenakan respon dari IC LM 335 lebih cepat dibandingkan dengan termometer.

\section{III.3. Program Logika Fuzzy dengan Implementasinya}

Pengujian program dengan implementasinya merupakan pengujian terhadap kontroler yang sudah diaplikasikan ke plant yang sebenarnya. Hasil yang dicapai adalah kita dapat melihat perilaku kontroler terhadap kestabilan sistem yang dalam hal ini adalah kenaikan temperatur.

Pada menu yang ditampilkan oleh monitor komputer, klik tombol 'Fuzzy' sehingga keluar form grafik pengujian sistem kontrol temperatur berbasis logika fuzzy. Masukkan setting point melalui keyboard kemudian tekan Enter. Sistem mulai bekerja dengan penentuan kondisi awal error $=0$. Begitu juga dengan dError $=0$. Grafik proses kestabilan temperatur dapat dilihat pada form grafik.

Dari beberapa pengujian yang dilakukan, hasilnya disajikan dalam bentuk grafik kestabilan yang dapat dilihat pada Gambar 3.2.

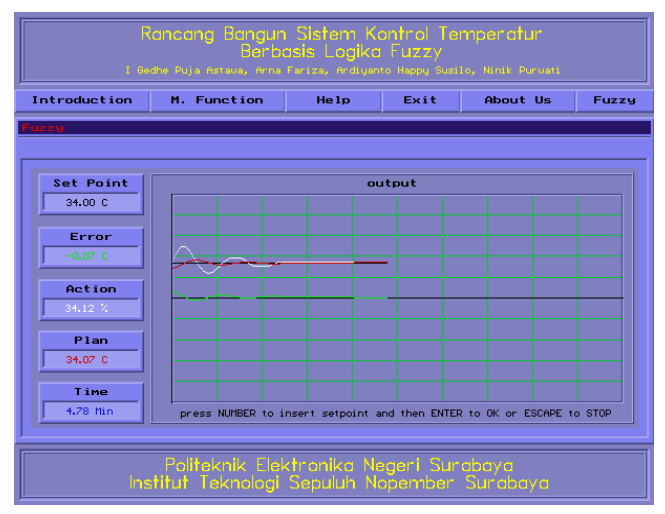

Gambar 3.2. Respon Kontroler

Dari grafik ini kita dapat melihat bagaimana kestabilan sistem mengguanakan kontrol logika fuzzy. Secara umum dapat dikatakan bahwa kontroler dapat berjalan dengan baik. 


\section{Kesimpulan dan Saran}

\section{IV.1. Kesimpulan}

Dari uraian di atas dapat disimpulkan bahwa respon kontrol yang dihasilkan mendekati setting point yang diberikan. Untuk setting point yang besar, prosesnya lebih lama bila dibandingkan dengan setting point yang kecil.

\section{IV.2. Saran}

Sebagai penutup dari buku proyek akhir ini penulis memberikan saran-saran kepada pembaca dengan tujuan segala kekurangan yang ada pada buku ini nantinya akan menuju kesempurnaan atau pengembangan sistem kendali logika fuzzy yang dapat dijelaskan sebagai berikut:

1. Penulis menyarankan serta berharap adanya pengembangan dan penyempurnaan dari proyek akhir ini di masa mendatang sehingga jenis kontroler semacam kendali logika fuzzy dan lainnya benar-benar diimplementasikan dalam membantu menyelesaikan persoalan-persoalan manusia, khususnya dalam bidang kontrol sehingga tidak hanya dalam penelitian saja, sehingga masyarakat akan percaya terhadap kehandalan jenis-jenis kontroler semacam ini.

2. Pada proyek akhir ini fuzzy yang digunakan adalah fuzzy biasa, sehingga apabila plant yang digunakan berbeda maka aturan-aturan yang ada pada sistem ini harus dirubah lagi sehingga didadapatkan aturan yang paling tepat, tentunya ini kurang fleksibel sehingga atas dasar tersebut penulis menyarankan agar di masa yang akan datang fuzzy dikembangkan menjadi fuzzy adaptif.

\section{Daftar Pustaka}

1. National Semiconduktor, National Data Acquisition Databook, 1995

2. Abdul Kadir, Pemrograman Dasar Turbo C untuk IBM PC

3. Mitsuteru Inove, Dedet Pramadihanto, Siti Halimah Baki, Miftahul Huda, Piranti Elektronika, Politeknik Elektronika Surabaya, ITS, 1993 